\title{
STANDARD PIAWAAIAN HALAL DI MALAYSIA MENURUT PERUNDANGAN, KELEBIHAN DAN KEKURANGAN
}

\author{
Mohd A1'Ikhsan Ghazali, ${ }^{\mathrm{a}, *}$ Siti Salwa Md. Sawari, ${ }^{\mathrm{b}}$ \\ ${ }^{a}$ Fakulti Tamadun Islam, Universiti Teknologi Malaysia. \\ ${ }^{\text {b }}$ Fakulti Tamadun Islam, Universiti Teknologi Malaysia. \\ *Corresponding author: salwa.sawari@gmail.com \\ Article history \\ Received:27/11/2014 \\ Received in revised form:15/2/2015 \\ Accepted:12/03/2015
}

\begin{abstract}
Currently, halal products show tremendous growth internationally. The increased production of various products in the market led to the need of halal standard parallel. Therefore, this research is conducted to study the position of the Malaysian halal standard from legal perspective. The study also explores the advantages and disadvantages of the halal standard that is being implemented in Malaysia. The results of the analysis show that the Malaysian legislation pertaining to halal has been designated as early as the 70s. However, the legislation exists separately in different legal sections namely Food Act 1983, Trade Descriptions Act 1972 and the Consumer Protection Act. From the analysis of the advantages of the halal standard, it can be inferred that Malaysian guidelines for halal products is comprehensive notably with the aid of existing Islamic law that help authorities to monitor halal products in Malaysia as well as in export countries that recognize halal standard adopted by Malaysia. However, to date, there are still some drawbacks associated with the quality assurance that has been highlighted by the media and thus indirectly portray negative impact on Malaysia's effort in developing the halal hub.
\end{abstract}

Keywords:Halal Standards, Legislation, Advantages and Disadvantages.

\begin{abstract}
Abstrak
Mutakhir ini produk halal di peringkat antarabangsa semakin menunjukkan peningkatan yang memberangsangkan. Dengan meningkatnya pengeluaran pelbagai produk di pasaran menyebabkan perlunya kepada standard halal yang selari. Sehubungan dengan itu, penyelidikan ini dijalankan bertujuan untuk mengkaji kedudukan standard piawaian halal Malaysia daripada sudut perundangan. Tambahan itu juga kajian turut meneroka kelebihan dan kekurangan standard halal yang dilaksanakan di Malaysia. Hasil daripada analisis yang dijalankan, kajian ini menunjukkan bahawa perundangan Halal di Malaysia sudah termaktub seawal tahun 70-an, namun begitu didapati penyusunan perundangan kurang sistematik kerana tercatat dalam seksyen perundangan yang berbeza iaitu Akta Makanan 1983, Akta Perihal Dagangan 1972 dan Akta Perlindungan Pengguna. Merujuk kepada analisis kelebihan standard piawaian halal Malaysia, dapat disimpulkan Malaysia mempunyai garis panduan produk halal yang kukuh dan menyeluruh di samping ruang lingkup undang-undang agama Islam sedia ada yang membantu pihak penguasa memantau produk halal di Malaysia serta di negara eksport yang mengiktiraf standard Halal yang diguna pakai oleh Malaysia. Namun begitu, sehingga kini masih terdapat beberapa kelemahan yang dikaitkan dengan jaminan kualiti halal masih lagi kedengaran di ruang media elektronik dan masih lagi kelihatan di helaian media cetak. Hal ini secara tidak langsung dilihat memberi kesan negatif kepada Malaysia dalam membangunkan hab halal.
\end{abstract}

Kata kunci: Piawaian Halal, Perundangan, Kelebihan dan Kekurangan. 


\subsection{PENDAHULUAN}

Islam merupakan Agama Persekutuan bagi negara Malaysia (Abdul RahmanMahmood, Kamaruddin Salleh, Ahmad Sunawari Long \&Faudzi NaimBadruddin, 2009). Sebagai sebuah negara Islam, isu makanan halal merupakan sesuatu yang amat dititik beratkan. Mutakhir ini produk halal di peringkat antarabangsa semakin menunjukkan peningkatan yang memberangsangkan(Che Mohd Zulkifli, 2013; Mohd Al'Ikhsan \& Siti Salwa, 2014). Perkara ini selari dengan meningkatnya jumlah umat Islam di dunia. Tambahan pula kesedaran di kalangan masyarakat dunia telah meningkat apabila mereka mula memahami bahawa konsep halal yang dibawa oleh Islam adalah bersifat universal, komprehensif dan bukan bersifat keagamaan semata-mata (Baharudin Othman, 2014). Bukan itu sahaja, banyak kajian telah membuktikan bahawa pemakanan halal mampu memberi kesan yang positif kepada pembinaan mental dan jasmani (Siti Salwa, Nurul Izzah \& Mohd Al'Ikhsan, 2014). Maka dengan ini, ia telah meningkatkan permintaan masyarakat dunia terhadap produk halal. Dengan meningkatnya pengeluaran pelbagai produk di pasaran menyebabkan perlunya kepada standard halal yang selari. Sehubungan dengan itu, penyelidikan ini dijalankan bertujuan untuk mengkaji kedudukan standard piawaian halal Malaysia daripada sudut perundangan. Di samping meneroka kelebihan dan kekurangan dalam perlaksanaan standard halal di Malaysia.

\subsection{METODOLOGI}

Kajian ini menggunakan kaedah kualitatif yang melibatkan proses memahami maksud secara mendalam. Kaedah pengkajian perpustakaan telah digunakan untuk mendapatkan hasil kajian. Menurut Suwanto (2013), kaedah perpustakaan ini ialah satu cara sistematik terhadap maklumat-maklumat yang ingin diperoleh daripada sumber bacaan yang diperoleh. Merujuk kepada kaedah pengkajian perpustakaan, terdapat dua jenis sumber yang boleh menghasilkan data; iaitu sumber primer dan sumber sekunder. Maka untuk membantu menyelesaikan ke semua objektif kajian, pengkaji telah menggunakan sumber sekunder. Antara sumber sekunder yang diguna pakai ialah, jurnal, keratan akhbar, dan dokumen berbentuk elektronik.

Dalam kajian ini terdapat beberapa proses yang dilalui oleh pengkaji meliputi proses pengumpulan maklumat, penyusunan maklumat, pengkategorian, analisis dan membuat kesimpulan. Pertamanya ialah, pengumpulan sumber-sumber sekunder berkaitan dengan tajuk piawaian standard halal di Malaysia, kemudian maklumat tadi disusun dan dikategori. Seterusnya, data tersebut dianalisis dan terakhir sekali ialah merangka laporan dan kesimpulan kajian.

\subsection{KEKEBALAN STANDARD HALAL DENGAN PERLINDUNGAN UNDANG-UNDANG}

Di Malaysia, Kementerian Perdagangan Dalam Negeri dan Hal Ehwal Pengguna (KPDN\&HEP) adalah kementerian yang bertanggungjawab dalam hal ehwal produk makanan selain Jabatan Kemajuan Malaysia (JAKIM) yang terlibat secara langsung dengan pengeluaran sijil halal. Objektif KPDN\&HEP adalah untuk menggalak dan memudahkan perdagangan dalam negara secara teratur dan sihat serta melindungi kepentingan pengguna. Sehubungan dengan itu beberapa peruntukan undang-undang berkaitan halal telah dirangka dan dikuatkuasakan sebagai contoh, pada tahun 1982, satu peraturan atau dasar telah diimplementasi iaitu semua daging import yang hendak dibawa masuk ke Malaysia mestilah halal.

Pada tahun 2004, Malaysia telah mengeluarkan standard halal MS1500:2004 iaitu garis panduan yang praktikal bagi industri makanan mengenai penyediaan dan pengendalian makanan halal atau peraturan asas produk makanan serta perdagangan atau perniagaan makanan. Garis panduan ini diguna bersama MS1480:1999 iaitu Keselamatan Makanan mengikut Prinsip Am Kebersihan Makanan, MS 1514: 2001. 
Bagi membicarakan aspek ruang lingkup undang-undang di Malaysia, boleh dirumuskan secara umumnya, peruntukan undang-undang berkaitan halal adalah terkandung dalam Akta Makanan 1983, Akta Perihal Dagangan 1972, Akta Perlindungan Pengguna 1999, Kanun Keseksaan, Akta Kesalahan Jenayah Syariah (Wilayah Persekutuan) 1997 dan Enakmen Kesalahan Jenayah Syariah Negeri-negeri, Perintah Perihal Dagangan (Penandaan Makanan) 1975 dan Perintah Perihal Dagangan (Penggunaan Perbahasan Halal) 1975 (Al'Ikhsan, 2014).

\subsection{Jabatan Kemajuan Islam Malaysia (JAKIM)}

Jabatan Kemajuan Islam Malaysia berfungsi untuk mengeluarkan sijil pengesahan halal. Menurut Portal Rasmi Halal Malaysia (2011), sijil pengesahan dan logo halal adalah bukti pengiktirafan kehalalan sesuatu produk makanan, minuman dan bahan gunaan orang Islam yang berlandaskan hukum syarak. JAKIM mengeluarkan sijil halal ini untuk mewujudkan standard halal yang seragam di Malaysia. Ia juga bertujuan membasmi kekeliruan dan keraguan yang wujud dalam kalangan pengguna Islam berkaitan dengan kehalalan atau kesucian sesuatu produk itu. Untuk membolehkan sesuatu produk memperoleh status sijil halal JAKIM, ia hendaklah mematuhi semua syarat-syarat yang ditetapkan dalam Garis Panduan Premis yang membuat penyediaan, pemprosesan atau masakan makanan, minuman dan bahan gunaan orang Islam yang diterbitkan oleh Jabatan Agama Islam Negeri masing-masing. Secara umumnya, di Malaysia, JAKIM merupakan badan yang telah menyediakan garis panduan produk halal secara komprehensif. Ini kerana garis panduan yang di sediakan oleh pihak JAKIM merangkumi prosedur pemeriksaan, pengesahan dan permohonan sijil halal, kelulusan, syarat-syarat, pemantauan dan penguatkuasaan. Berikut adalah plot proses persijilan halal di Malaysia (Portal Rasmi Halal Malaysia, 2011);

1. Mendaftar secara atas talian dengan mewujudkan ID dan katalaluan.

2. Sahkan akaun dalam tempoh 24 jam atau 1 hari.

3. Tempoh penghantaran dokumen sokongan dalam masa 5 hari bekerja selepas permohonan atas talian dihantar.

4. Setelah dokumen diterima, status permohonan akan bertukar kepada menunggu dokumen lengkap.

5. Semakan perlu dilakukan bagi memastikan dokumen lengkap. Jika dokumen tidak lengkap, status akan bertukar kepada tidak lengkap dan pihak pemohon perlu menghantar pembetulan atau maklum balas dalam tempoh 5 hari bekerja. Kemudian permohonan boleh diproses dalam tempoh 1-5 hari bekerja mengikut jumlah produk/menu/premis. Surat caj akan dikeluarkan.

6. Caj pemprosesan akan dikenakan, dan perlu dibayar dalam tempoh 14 hari bekerja.

7. Resit akan dikeluarkan dalam tempoh satu hari selepas diterima.

8. Status akan bertukar ke proses audit. Audit akan dijalankan dalam tempoh 30 hari selepas bayaran diterima.

9. Proses kelulusan mengikut tarikh Mesyuarat Panel Persijilan dijalankan.

10. Jika diluluskan sijil akan dikeluarkan dalam tempoh 5 hari bekerja. Jika gagal, pihak pemohon akan dimaklumkan melalui surat rasmi. 


\subsection{KELEBIHAN PIAWAIAN STANDARD HALALMALAYSIA}

Malaysia menjadi pengerusi kepada Persidangan Negara-negara Islam (OIC) dan telah menjadi hab Halal Dunia pada tahun 2010. Sejajar dengan itu, Malaysia merupakan negara pertama dunia yang memperkenalkan standard halal secara menyeluruh dan meluaskan konsepnya melalui penggunaan ehalal. Ini dapat dilihat melalui Standard Malaysia, standard makanan halal merangkumi aspek pengeluaran, penyediaan, pengendalian dan penyimpanan. Ia mengandungi beberapa kriteria yang perlu dipatuhi iaitu Garis-garis Panduan yang Praktikal bagi Industri Makanan mengenai Penyediaan dan Pengendalian Makanan Halal, Peraturan Asas bagi Produk Makanan serta Perdagangan atau Perniagaan Makanan di Malaysia (MS 1480:1999), Keselamatan Makanan Mengikut Analisis Bahaya dan Titik Kawalan Kritikal "Hazard Analysis and Critical Control Point”(HACCP), MS1514:2001 Prinsip Am Kebersihan Makanan dan MS1500:2009 Makanan Halal - Pengeluaran, Penyediaan, Pengendalian dan Penyimpanan - Garis Panduan Am.

Standard halalnya telah diguna pakai di peringkat antarabangsa dan mendapat kepercayaan negaranegara OIC sebagai peneraju standard halal di antara negara-negara Islam (Rozailin, Zainalabidin, Golnaz, Mad Nasir, \& Juwaidah, 2014). Selain itu, kelebihan MS1500:2009 ialah penekanan terhadap nilai-nilai Islam dan pegangan terhadap prinsip Islam seperti menjamin kualiti dan standard produk dan perkhidmatan yang berterusan yang akan dipastikan melalui surveillance audit ( pengawasan). Proses penghasilan makanan, aspek pengeluaran, penyediaan, pengendalian dan penyimpanan juga menjadi garis panduan kepada pengeluar dalam memastikan produk yang dihasilkan adalah benar-benar menepati maksud halal yang ditetapkan oleh Islam.

Malaysia telah mendahului negara-negara lain dalam menghasilkan standard Halal. Hal ini dapat dilihat apabila Bahagian Hab Halal, Jabatan Agama Islam Malaysia (JAKIM) telah mencipta sejarah dalam Industri Halal Global dengan menjadi badan persijilan pertama di dunia yang mengguna dan mengesahkan pengeluaran produk farmaseutikal halal. Walaupun masih baru, MS2424:2012 mampu membantu pengeluar atau pengilang menghasilkan produk ubatan patuh Syariah. Selain itu, ianya juga mengandungi garis panduan untuk memastikan kualiti pengurusan (QM) dalam menghasilkan barangan atau produk ubatan yang baik dan bagus. Sebelum terdapatnya Standard Halal Farmaseutikal ini,para pengeluar merujuk dan menguna pakai Standard Makanan Halal. Walau bagaimanapun, kaedah tersebut adalah tidak ideal kerana Standard Makanan Halal tidak diolah untuk menangani kompleksiti yang berkaitan dengan sektor farmaseutikal.

Standard halal merupakan suatu langkah dalam memastikan pengesahan dan persijilan halal yang diberi mematuhi sebenar-benar pematuhan mengikut ketetapan Syariah (Mohd Al'Ikhsan \& Siti Salwa, 2014). Ini kerana, badan-badan atau organisasi yang dilantik secara rasmi bertanggungjawab dalam memastikan garis panduan produk halal itu diikuti. Sebagai contoh di Thailand, walaupun masyarakat Islamnya hanyalah golongan minoriti, kerajaan telah melantik Jawatan kuasa Pusat Islam Thailand sebagai badan berkanun yang bertindak bagi memastikan kelancaran dan kecekapan pengurusan halal di negara berkenaan.

Bagi Malaysia pula, usaha untuk membangunkan sesuatu piawaian industri terletak di bawah tanggung jawab SIRIM Berhad. SIRIM Berhad menerusi Jawatankuasa-jawatankuasa Piawaian Industri "Industry Standards Committee"(ISC) yang ditubuhkannya telah membangunkan pelbagai piawaian termasuk MS1900:2005 Quality Management Systems: Requirement from Islamic Perspectives atau ringkasnya MS1900:2005. MS1900:2005 ini merupakan salah satu piawaian halal yang berjaya dihasilkan oleh Jawatankuasa Teknikal Pengurusan Islam yang bernaung di bawah Jawatankuasa Standard Industri bagi Standard Halal (ISC I), iaitu salah satu ISC yang diwujudkan oleh SIRIM Berhad. Walau bagaimanapun, standard halal ini telah diberi tanggungjawab kepada Jabatan Kemajuan Islam Malaysia (JAKIM) dalam memastikan persijilan halal dan memantau industri halal di Malaysia. Antara agensi yang terlibat dalam menggubal standard MS1500:2009 ialah Persekutuan Pekilang Malaysia, Institut Kualiti Malaysia, Universiti Islam Antarabangsa Malaysia, Universiti Putra Malaysia serta 
Universiti Teknologi Mara, Institut Penyelidikan dan Kemajuan Pertanian Malaysia, Jabatan Standard Malaysia, Jabatan Perkhidmatan Veterinar, Kementerian Kesihatan Malaysia, dan Sirim Berhad (Shawkath, 2010). Ini membuktikan kesungguhan Malaysia dalam memastikan standard halal yang dibangunkan dapat diterima pakai bukan sahaja oleh pengguna dan pengusaha Islam tetapi oleh semua golongan masyarakat terutamanya di Malaysia yang mempunyai kepelbagaian bangsa dan agama.

Kelebihan Piawaian Halal Malaysia juga terletak pada penggunaan Sistem Jaminan Halal (SJH) yang membantu memastikan status halal bahan mentah, proses dan produk yang mendapat pengiktirafan sijil halal adalah dijaga dan dipantau sepanjang masa secara berterusan (Portal Halal Malaysia, 2013). Hal ini dapat mengukuh serta menguatkan lagi standard halal yang digunakan kerana faktor geografi Malaysia yang spesifik dan strategik membantu dalam memastikan halal di seluruh negara setara dan seragam. Keadaan ini berbeza dengan negara-negara yang mempunyai bentuk muka bumi yang luas dan berpulau seperti negara Indonesia, kerana kemungkinan memastikan keseragaman standard halal itu sukar dan mengambil masa yang lama oleh pihak yang telah dilantik. (Mohd Al'Ikhsan \& Siti Salwa, 2014).

\subsection{KELEMAHAN PIAWAIAN STANDARD HALALMALAYSIA}

Seiring dengan perkembangan positif piawaian halal MS1500:2009 yang telah menjadi dokumen rujukan rasmi dalam proses persijilan halal di Malaysia. Piawaian MS1500:2009 terus mendapat sambutan dalam industri makanan halal sehingga di peringkat global malah di negara bukan Islam juga. Namun begitu, sehingga kini masih terdapat beberapa kelemahan yang dikaitkan dengan jaminan kualiti halal masih lagi kedengaran di ruang media elektronik dan masih lagi kelihatan di helaian media cetak. Hal ini secara tidak langsung dilihat memberi kesan negatif kepada Malaysia dalam membangunkan hab halal.

Merujuk kepada beberapa pembacaan dan penelitian, antara isu yang dilihat telah menyumbang kepada kekangan pengurusan kualiti standard halal melalui penggunaan piawaian halal MS1500:2009 ialah mengenai isu integriti halal dalam operasi pengeluaran makanan. Secara komprehensifnya, perkara seperti ini perlu diambil perhatian dari keseluruhan aspek jaringan bekalan makanan halal iaitu dari ladang hingga ke meja makan (farm-to-fork). Hal ini termasuklah penglibatan individu atau dinamakan sebagai pekerja, pengusaha atau pengurus yang mana integriti mereka dalam mengikuti standard yang telah ditetapkan diragui. Ini kerana, kebanyakan pengusaha makanan tidak lagi mengamalkan piawaian kualiti makanan halal yang ditetapkan oleh MS1500:2009 setelah produk mereka memperoleh pengiktirafan halal dari JAKIM. Walaubagaimanapun, International Halal Integrity Alliance (IHIA) sebuah badan bukan kerajaan telah ditubuhkan bagi memantau tahap integriti dalam melaksanakan standard halal dengan lebih efisien (Mohd Al' Ikhsan, 2014).

Selain itu, antara kelemahan yang dapat dilihat dalam penggunaan standard halal ialah kelemahan Malaysia dalam meraikan perbezaan mazhab. Umum mengetahui bahawa Malaysia mengguna pakai mazhab Syafie dan Sunnah Wal Jamaah berdasarkan kepada keputusan Majlis Mesyuarat Raja-raja kali ke-13 pada 3 Disember 1984 bahawa mazhab yang diamalkan di negara ini ialah Syafie dan Sunnah Wal Jamaah. Oleh itu penyebaran fahaman mazhab lain hendaklah dikawal dan aktiviti mereka dibenarkan kepada pengamalan bukan penyebaran (Hazayani, 2013).

\subsection{KESIMPULAN}

Berdasarkan kepada perbincangan di atas, tiga perkara utama dapat dirumuskan iaitu, pertama menjurus kepada perspektif undang-undang mengenai standard halal yang digunakan di Malaysia, kedua kelebihan standard halal Malaysia dan yang terakhir berkisar kepada kekurangan yang wujud. Kajian ini telah membuktikan walaupun perundangan halal di Malaysia sudah termaktub seawal tahun 1980, ianya kurang sistematik kerana tercatat dalam seksyen perundangan yang berbeza iaitu; Akta Makanan 1983, Akta Perihal Dagangan 1972 dan Akta Perlindungan Pengguna. Analisis kelebihan standard piawaian halal Malaysia menunjukkan bahawa Malaysia mempunyai garis panduan produk halal yang kukuh dan menyeluruh di samping ruang lingkup undang-undang agama Islam sedia ada yang membantu pihak 
penguasa memantau produk halal di Malaysia serta di negara-negara eksport yang mengiktiraf standard halal yang diguna pakai oleh Malaysia. Namun begitu, sehingga kini masih terdapat beberapa kelemahan berkaitan dengan jaminan kualiti halal yang masih lagi kedengaran di ruang media elektronik dan masih lagi kelihatan di helaian media cetak. Hal ini secara tidak langsung dilihat memberi kesan negatif kepada Malaysia dalam membangunkan hab halal. Usaha-usaha memantapkan lagi standard Halal Malaysia harus dijalankan bagi menambahbaik segala kekurangan yang ada di samping menjadi negara contoh dalam mengeluarkan standard halal yang diiktiraf oleh dunia.

\section{Rujukan}

Abdul Rahman Mahmood, Kamaruddin Salleh, Ahmad Sunawari Long \& Faudzi Naim Badruddin, (2009). Penerimaan bukan Islam terhadap proses Islamisasi di Malaysia. Jurnal Hadhari, 2, 33-51.

Baharudin Othman. (2014). Why do food industry need Halal Assurance Management System? A Malaysian approach. Proceeding 5th Annual Conference, International Graduate Conference on Engineering, Science and Humanities 2014.

Che Mohd Zulkifli, Che Omar. (2013). Challenges and marketing strategies of halal product in Malaysia. Interdiscpline Journal of Research of Business. 3(2), 11-17.

Hazayani Zakaria. (2013, 23 September). Jangan terpengaruh mazhab rumit. Harakah.

Malaysian Standard MS 1500:2009, (2009). Makanan halal - Pengeluaran, penyediaan, pengendalian dan penyimpanan - Garis panduan umum (Semakan Kedua), Jabatan Standard Halal.

Mohd Al'Ikhsan Ghazali. (2014). Piawaian halal: kajian perbezaan antara Malaysia dengan negara luar. Research Project. Universiti Teknologi Malaysia.

Mohd Al'Ikhsan Ghazali \& Siti Salwa Md. Sawari (2014). Kajian perbandingan piawaian halal antara Malaysia dan Negara Brunei. Proseding Social Sciences Postgraduate International Seminar. University Science Malaysia. DOI: 10.13140/2.1.2096.3520

Mohd Al'Ikhsan Ghazali \& Siti Salwa Md Sawari (2014). Penemuan amalan standard halal di negaranegara Asia Tenggara. UMRAN-International Journal of Islamic and Civilizational Studies, 1(1).

Portal Halal Malaysia. (2013). Sistem jaminan halal. http://www.halal.gov.my/v3/index.php/ms/garispanduan/sistem-jaminan-halal

Portal Rasmi Halal Malaysia. (2011). Aliran kerja proses pensijilan halal Malaysia. http://www.halal.gov.my/v3/index.php/ms/aliran-kerja-proses-pensijilan. 23/1/2014.

Rozailin Abdul Rahman, Zainalabidin Mohamed, Golnaz Rezai, Mad Nasir Shamsudin, \& Juwaidah Sharifuddin. (2014). Exploring the OIC food manufacturer intention towards adopting Malaysian halal certification. American Journal of Food Technology. (2014). DOI: 10.3923/ajft.2014.

Siti Salwa Md.Sawari, Nurul Izzah Mustapha \&Mohd Al'Ikhsan Ghazali (2014). The impact of halal food on physical and mental health. Proseding International Seminar on Islamic Law, Economic, Education and Science Issues. Dewan Senat, Universiti Teknologi Malaysia. DOI: $10.13140 / 2.1 .1291 .4244$

Shawkath Azde. (2010, 3 Januari). Sijil halal JAKIM ikut MS1500. Kosmo.

Suwanto, S. A. (2003). Kajian pemakai perpustakaan. Disampaikan pada Diklat Fungsional TOT Perpustakaan Propinsi Jateng. 